because they have been successfully paired with females in the laboratory and offspring of both sexes have resulted.

There can be no reasonable doubt, therefore, that all sawfly males are of one kind in that they originate from unfertilised haploid eggs which may be laid by virgin females or by inseminated females.

This finding affords a clue to other problems of sawfly parthenogenesis and its evolution, but these will not be explored at this juncture, their discussion being deferred for the paper, now in preparation, which is to deal, in detail, with the matter of this letter together with other features of sawfly spermatogenesis.

It remains to make grateful acknowledgements to the British Association for a grant in aid, and to the following, all of Armstrong College : The Research Endowment Fund Committee for the provision of a Leitz Binocular Microscope, Prof. A. Meek for the facilities of his zoological laboratories, including the services of the steward, Mr. D. C. Geddes, and Dr. J. W. Heslop Harrison, who checked my cytological conclusions.

Armstrong College (University of Durham), Newcastle-on-Tyne, September 20.

\section{On the Advancement of Science by Published Papers.}

UNDOUBTEDLY science is kept alive by teaching; and without good teaching, there can be but little discovery. Edison, for instance, when young, possessed and studied Faraday's masterly researches on electricity.

The present writer has been engaged in scientific research for eighteen years or so. He does not pretend, however, to have observed all the following rules, of the importance of which he became cognisant by degrees. The foundation of the co-operative fabric of science and scientific discovery has been built up by the work of the early " missionaries of science," when research entailed more or less of a martyrdom. It is hoped that we can pass on to posterity this edifice of science, undecayed and even embellished, now that research is a privilege and a giver of prestige. If we do not, the position of science and scientific work may deteriorate without limit.

(I) The truth, and nothing but the truth, but never the whole truth for publication. One must omit trivialities. Our scientific magazines are now sometimes more or less packed with never-to-be-utilised details, most of which perhaps would have better rested in the notebook. The penalty for nonobservation of this rule is the, probably now imminent, cessation of publication, except in the form of abstracts.

(2) It is perhaps unethical for a research worker, as for a medical man, to advertise. Plethoric papers, pictures not absolutely necessary, repetitions in different magazines, references mainly to one's own work, and unneeded elaboration or enlargement of figures, seem to partake of the nature of advertising. The penalty for infraction is the introduction of competitive business methods into science as an ideal; instead of the co-operative aims, which have produced such good results in the past.

(3) Mere facts, however new, are often (though not always) of perceptible scientific value only when their discoverer, or some one else, has demonstrated their relations to other facts, or to a theory or hypothesis of value. If they have no such demonstrable relations, they are probably " trifling though true." The penalty is again the ending of magazine publication in extenso.
(4) The repetitions and confirmations of a discovery on similar or related material are of sufficient scientific interest to warrant full publication only to a certain degree of repetition. Whether this is ten or a hundred times, the point is at length reached when only the accounts of exceptions to the rule are worth full publication. The penalty is again the flooding of magazines, and the future reduction to abstract publication.

(5) The publication of a working hypothesis by one who has discovered a sufficient amount of relevant fact is welcome, and indeed almost necessary. (A working hypothesis is one that is immediately to be tested.) But a mass of untested hypotheses is readily producible ; and may be aimless, except to fill space. A flood of hypotheses, which cannot be immediately tested, may be a brake on the progress of a science. Since it is easier, for many of us, to spin hypotheses than to make discoveries, the penalty for the appreciation and prestige of this form of mental exercise is the partial, or even complete, cessation of experiment.

(6) It is probably unethical to claim credit or priority for an untested hypothesis (mostly for writers in the distant past), to the prejudice of those who have borne the full burden of testing it. A writer who has published, among a number of unworkable hypotheses, one which has subsequently been used as a successful working hypothesiș, does not apparently deserve to be cited. Perhaps one should not attach priority to any untested hypothesis, but only to true working hypotheses.

(7) It is generally recognised that, in a serious scientific paper, citations of a genuinely relevant previous work should be complete, so far as they are not known to all readers. Even excessive and pedantic citation is a fault on the right side. But surely much space might be saved by referring to standard numbered annual lists of scientific papers. The penalty for lack of citation is, of course, to leave it doubtful as to how much the writer has himself discovered. It leads also to the isolation of workers or countries. But excessive citations again overload the magazines.

(8) A form of scientific co-operation consists in the sending of separate copies of papers, in not readily accessible magazines, to other interested workers. This has now extended to all magazines, even those accessible to everybody. Stanley Hall regards it as a means of working up a personal following or constituency; in other words, it is now an advertising method. Perhaps as much as anything else, it injures the circulation of the scientific magazines.

These and other similar rules are, of course, well known to, and observed by, many experienced workers.

Huntington, N.Y.

\section{The Band Spectra associated with Garbon.}

IN an interesting letter to NATURE (August 8, p. 207), Prof. Birge has directed attention to a band system which I described as a "New Band System" in Proc. Roy. Soc., A, vol. I08, p. 349 (1925). More recently (NAture, Sept. 5, p. 360) M. Baldet has written with reference to this system, pointing out that three of the six bands I recorded were measured and described by him in C.R., vol. I78, p. I 525 (1925). I should like to take the opportunity of saying that at the time of writing my paper I was not aware of this work of M. Baldet, and to him must be given the credit for the first recorded measurements of the system. At the same time, the discovery of this spectrum was first recorded by Prof. Merton and myself in Proc. Roy. Soc., A, vol. Io3, p. 389 (I923), 